Revista del Centro de Investigación de la Universidad La Salle

Vol. 14, No. 54, Julio-Diciembre, 2020: 167-200

DOI: http://doi.org/10.26457/recein.v14i54.2652

\title{
Covid-19: conocimientos y explicaciones causales desarrolladas por la población mexicana. Resultados preliminares ${ }^{1}$
}

\section{Covid-19: knowledge and causal explanations developed by the Mexican population. Preliminary results}

\author{
María Graciela Freyermuth Enciso ${ }^{2}$ \\ Centro de Investigaciones y Estudios Superiores en Antropología Social. Unidad \\ Regional Sureste (México) \\ José Alejandro Meza Palmeros \\ Centro de Investigaciones y Estudios Superiores en Antropología Social. Unidad \\ Regional Noreste (México) \\ Gabriel Armando Torres López \\ Asesoría y Capacitación en Salud A.C. (México)
}

Recibido: 29 de mayo de 2020 Aceptado: 17 de septiembre de 2020 Publicado: 20 de noviembre de 2020

\section{Resumen}

El objetivo del trabajo es describir y analizar los conocimientos y las concepciones causales desarrolladas por la población mexicana ante la pandemia de COVID-19. Se presentan los

\footnotetext{
${ }^{1}$ Este trabajo fue financiado por el Consejo Nacional de Ciencia y Tecnología (CONACYT) a través de la convocatoria 2020-1 APOYO PARA PROYECTOS DE INVESTIGACIÓN CIENTÍFICA, DESARROLLO TECNOLÓGICO E INNOVACIÓN EN SALUD ANTE LA CONTINGENCIA POR COVID-19. Proyecto número 000000000312266

${ }^{2}$ Email: gracielafreyermuth54@ hotmail.com
}

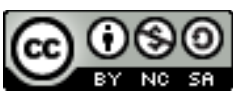

Revista del Centro de Investigación. Universidad La Salle por Dirección de Investigación. Universidad La Salle Ciudad de México se distribuye bajo una Licencia Creative Commons Atribución-NoComercial-Compartirlgual 
resultados preliminares en el marco de una investigación más amplia de la percepción colectiva del riesgo ante tal situación. Se diseñó y se aplicó una encuesta digital que fue respondida por 963 personas de una muestra por conveniencia, mediante una encuesta en línea.

Se identificó que los conocimientos que la población manifiesta tienen que ver sobre todo con aspectos epidemiológicos (hasta en 67\%) y clínicos (52\%) de la pandemia. En cuanto a la causalidad, las respuestas de las personas encuestadas se agruparon en cuatro modelos explicativos: moral (40.3\%), determinista (38.7\%), agencial (17.8\%) y xenofóbico (3.1\%). La limitación más importante del estudio radica en que se tuvo poco control sobre la muestra por tratarse de una encuesta difundida en medios digitales.

El trabajo presenta hallazgos que contribuyen a comprender la diversidad de los comportamientos de la población mexicana ante la pandemia. Entre estos, la adopción o no de las prescripciones propuestas por las autoridades sanitarias. El trabajo constituye un insumo para el diseño de estrategias de promoción de la salud y de comunicación de los riesgos. Hallazgos de relevancia son el alto grado de penetración del discurso biomédico en los conocimientos y modelos explicativos de la población encuestada, así como la importancia de la experiencia directa de una situación amenazante en la percepción del riesgo.

Palabras claves: percepción del riesgo; conocimientos; modelos explicativos; COVID-19; encuesta digital. 


\section{Abstract}

The objective of the work is to know, describe and analyze the knowledge and causal concepts developed by the Mexican population in the face of the COVID-19 pandemic. Preliminary results are presented in the framework of a broader investigation, aimed at inquiring about the collective perception of risk in such situation. A digital survey was designed and applied, and was answered by 963 people from a sample for convenience, initiated from the networks of the authors of the article.

It was identified that the knowledge that the population manifests has to do predominantly with epidemiological (up to 67\%) and clinical (52\%) aspects of the pandemic. Regarding causality, the responses of the respondents were grouped into four explanatory models: moral (40.3\%), deterministic (38.7\%), agency (17.8\%) and xenophobic (3.1\%). The most important limitation of the study is that there was little control over the sample, since it was a survey disseminated by digital media.

The work presents findings that contribute to the understanding of the population behaviors that the pandemic has caused in the Mexican population, and that can be inputs for the design of health promotion and risk communication strategies. Relevant findings are the high degree of penetration that biomedical discourse has in the explanatory knowledge and models of the surveyed population, as well as the importance of direct experience of a threatening situation in the perception of risk.

Keywords: risk perception; knowledge; explanatory models; COVID-19; digital survey. 


\section{Introducción}

En diciembre de 2019 apareció en Wuhan, provincia de Hubei, China, un brote de enfermedad respiratoria aguda (Wang et al., 2020). Inicialmente, en los primeros días de enero de 2020, se dio a conocer una neumonía de origen desconocido, el genoma de un virus nuevo, aislado de algunos pacientes afectados: el Coronavirus-2 del Síndrome Respiratorio Agudo Severo, llamado SARS-COV-2 por el Comité Internacional sobre Taxonomía de los Virus (World Health Organization [WHO], 2020b), causante de la enfermedad hasta ese momento desconocida. Poco después sería designada por la Organización Mundial de la Salud (OMS) como Enfermedad por Coronavirus 2019 (COVID-19, acrónimo de Coronavirus Disease-2019) (Zhou et al., 2020).

El 30 de enero, la OMS declaró el brote de COVID-19 como una Emergencia de Salud Pública de Preocupación Internacional, cuando los casos confirmados eran 9826 en China y 106 fuera de este país (WHO, 2020b). El 11 de marzo, la propia OMS caracterizó la COVID-19 como una pandemia, cuando el número de casos fuera de China se había triplicado en las últimas dos semanas. Existían ya más de 228000 casos en 114 países, y el número de muertos ascendía a 4 291(wHO, 2020c).

La pandemia se ha propagado por el planeta al crecer en forma exponencial, y ha sobresaturado los sistemas de salud, incluso de los países desarrollados, lo que ha exigido la imposición de medidas drásticas de confinamiento a la población, y ha hecho temer por la grave crisis que la parálisis de la actividad económica acarreará. Al momento de escribir estas líneas, el número de casos comprobados a nivel global ascendía a 5103 006, y el de defunciones, a 333401 (wHO, 2020a).

A diferencia de lo ocurrido con otras epidemias, la situación suscitada por la crisis de COVID-19 ha generado un flujo permanente de información mediática (televisión, prensa escrita y redes sociales como Facebook) que, aunque propiciada por las autoridades sanitarias, es reproducida por múltiples voces, desde voceros de conocidos medios de información, hasta usuarios influyentes en las redes sociales digitales. Es posible afirmar que la interacción de la población y las autoridades sanitarias derivada de la actual pandemia es inédita. 
A partir de febrero, las autoridades de gobierno en los ámbitos nacional y estatal comenzaron a difundir incesantemente información acerca de la pandemia con un considerable contenido epidemiológico. Si bien es cierto que los medios de comunicación reproducen de manera constante información concerniente a problemas de salud, contribuyendo así a configurar distintas percepciones del riesgo (Mairal, 2011; Menéndez \& DiPardo, 2009), el empleo de medios digitales ha posibilitado la intervención de la ciudadanía en la construcción discursiva (Drake, 2006; Lupton, 2012), y ha generado un fenómeno que puede caracterizarse como de polifonía (Bajtín, 2011). Debido al empleo masivo de las redes sociales electrónicas, estas se han convertido en un punto importante de interacción de las autoridades sanitarias y diversos sujetos discursivos. A través de estos medios, el contenido informativo referente a la pandemia se reproduce, se cuestiona y se modifica.

Este tipo de interacción polifónica con la información contribuye a producir saberes, significados y explicaciones de muy distinta naturaleza entre los sujetos y, por lo tanto, una percepción del riesgo heterogénea. Como se ha podido apreciar en los medios de comunicación, esta variabilidad perceptiva ha desembocado en prácticas poblacionales diversas, algunas nocivas para los mismos sujetos. Desde compras masivas de papel higiénico, gel antibacterial, cubre bocas y jabón -lo que ha determinado la escasez de estos productos-, hasta aquellas que atentan directamente contra la vida y la dignidad de las personas, como las agresiones contra trabajadores de la salud o contra personas portadoras, o supuestamente portadoras, del SARS-COV-2.

Por otro lado, mientras que algunos miembros de la población han asumido las prescripciones formuladas por las autoridades sanitarias nacionales o extranjeras particularmente el lavado de manos, el distanciamiento social y el uso de mascarillas-, otros las han ignorado o han adoptado prácticas que no coinciden con las expectativas de dichas autoridades. Por ejemplo, negarse a que se les tomen muestras cuando son considerados casos sospechosos.

Por otro lado, la pandemia ha hecho confluir situaciones que desencadenan otros riesgos poblacionales, como las crisis económicas. Si bien el discurso biomédico enfatiza constantemente que la salud es prioritaria, las propias autoridades sanitarias configuran el riesgo de la epidemia a partir de valoraciones ajenas a la salud en términos estrictos. Así, las 
consecuencias económicas y políticas son incorporadas a los mensajes dirigidos a la población, lo que resalta el carácter complejo de la percepción del riesgo.

Con percepción del riesgo nos referimos a la serie de representaciones y prácticas que se construyen a partir de una situación identificada como peligrosa por una colectividad. Siguiendo las propuestas analíticas de Douglas (2002) y Beck (1992), consideramos que el concepto de riesgo es polisémico e incluye valoraciones morales, políticas y económicas cuya relevancia es el carácter orientador para la adopción de determinados comportamientos.

Sin embargo, la población responde de distintas maneras a la noción de peligro. Sus respuestas están mediadas por el grado de confianza o autoridad que suponen para ellos los expertos, así como por valoraciones propias fundamentadas en un conocimiento tanto colectivo como biográfico (Douglas, 2002). Por otro lado, la población cuestiona constantemente el juicio de los expertos acerca del riesgo. En su propia reflexividad, discrimina entre distintas fuentes de información, lo que constituye uno de los elementos con que se negocia la información recibida y se construye un cuerpo propio de conocimientos acerca de un determinado riesgo en el contexto de su vida cotidiana.

En un trabajo etnográfico, Davidson, Frankel y Smith (1992) muestran el constante cuestionamiento de las personas a la información biomédica al contrastarla con un acervo de experiencias que los autores denominan epidemiología local. Por ejemplo, respecto al consumo de tabaco, es frecuente que la población identifique contradicciones entre las aseveraciones biomédicas y lo experimentado frente a sus referencias cercanas, de modo que identifican que una cierta persona fumadora fue longeva mientras que otra, no fumadora, que además era delgada y deportista, falleció del corazón.

Los conocimientos de la población respecto a un determinado fenómeno le permiten estructurar ciertas atribuciones causales a partir de las cuales configura explicaciones. Estas explicaciones permiten a los individuos y a los colectivos sentirse en control del peligro, y actuar para prevenirlo. Los aspectos analizados en el presente trabajo -los conocimientos y las explicaciones causales de la población- son centrales en la percepción del riesgo inicial de la pandemia, pues conforman una estructura valorativa que permite a los sujetos determinar la naturaleza de un evento y la amenaza que representa, y actuar en consecuencia. En este sentido, retomamos el concepto de modelo explicativo (Kleinman, 1980) como una 
herramienta que permite agrupar y tipificar la serie de atribuciones causales que se le han otorgado a la crisis de la COVID-19.

Partimos del supuesto de que el conocimiento de la manera en que se configuran distintas percepciones del riesgo puede contribuir a comprender las prácticas poblacionales ante la situación. Esta perspectiva se ha empleado ampliamente en la literatura de las ciencias sociales (Bradbury, 1989; Davidson, Frankel \& Smith, 1992; Douglas, 2002; 2003; Lupton, 2013).

\section{Metodología}

\subsection{Participantes}

Se trata de un estudio descriptivo, prospectivo y transversal, realizado a partir de un cuestionario aplicado entre el 29 de marzo y el 17 de abril de 2020. El cuestionario comenzó a promoverse el 29 de marzo, principalmente a través de la aplicación WhatsApp (WA) y el correo electrónico (correo-e). Ese primer día obtuvimos el mayor número de respuestas; para el 3 de abril habíamos conseguido 97\% del total, y en adelante las respuestas empezaron a declinar. El corte para el análisis se hizo el 17 de abril. No se utilizaron otros medios electrónicos -como Facebook o Twitter-para su difusión.

La encuesta incluyó una breve presentación del objetivo de la entrevista y de la institución de adscripción de los investigadores del estudio. Los participantes se caracterizan por contar con un correo-e o un teléfono celular, y por saber leer y escribir.

En 2019, 56\% de los hogares mexicanos contaban con internet, $70.1 \%$ eran usuarios de internet, y 92.5\%, de telefonía celular (ENDHUIT, 2019). La promoción de las encuestas a través de WA y correo-e tiene el inconveniente de que, en la primera fase de su difusión, la población encuestada forma parte de las redes de las personas que lanzaron la encuesta y de las redes de esa red primaria, lo que propicia la respuesta predominante de un grupo con afinidades sociales, económicas, ideológicas o académicas. 


\subsection{Instrumento de recolección de datos}

\subsubsection{Objetivo principal}

La encuesta tuvo por objetivo principal conocer el impacto de las medidas de distanciamiento social que se tomaron en México -anunciadas entre el 16 y el 24 de marzo-, y la Jornada Nacional de Sana Distancia. Por ello, se buscó información respecto de los conocimientos de la población sobre la pandemia, y de su percepción del riesgo - a la luz de la composición familiar, la presencia de comorbilidades, y las posibilidades de quedarse en casa-, con relación a la aplicación de las medidas de distanciamiento social, considerando la estructura familiar, la ocupación, la adscripción religiosa y la sociabilización.

\subsubsection{Diseño}

La encuesta se diseñó exprofeso y se discutió con un grupo de trabajo con experiencia en la evaluación de los sistemas de salud. Del 23 al 27 de marzo se hizo un piloto en papel y se contrató la plataforma Survio para recolectar la información.

Aunque no hay una regla sobre cuándo utilizar este tipo de aproximaciones, una encuesta en línea es un instrumento apropiado si atendemos las condiciones actuales de distanciamiento físico y aislamiento, que dificultan la entrevista cara a cara. Se considera que en este tipo de encuestas un número de preguntas acotadas y cerradas es más confiable para evitar el riesgo de un número importante de deserciones. Sin embargo, se incluyeron preguntas abiertas para conocer la percepción del riesgo.

\subsubsection{Estructura}

La encuesta consta de dos partes:

- La primera incluye las características sociodemográficas de las personas participantes: edad, estado civil, sexo, ocupación, religión, si es hablante de una lengua indígena, entidad de residencia, municipio de residencia, lugar de origen.

- La segunda incluye varios bloques de preguntas para indagar en los conocimientos de la población encuestada acerca de la COVID-19, su percepción del riesgo y su dinámica social. 
La encuesta constó de 55 reactivos, de los cuales 20 eran preguntas abiertas, y en el resto se debía seleccionar una respuesta en una lista de opciones. Ello implicó un mayor esfuerzo para las personas encuestadas, en particular en los siete reactivos sobre sus conocimientos, interpretaciones, afectaciones personales y el impacto vital por la pandemia.

En este artículo se describen y analizan 20 reactivos que incluyen la distribución geográfica y las características demográficas y del estado de salud de las personas encuestadas (de ellas o de sus familiares), a fin de que los lectores puedan inferir su representatividad. Sin embargo, el artículo destaca dos de las preguntas formuladas:

- ¿Qué sabe usted del coronavirus?

- ¿Por qué cree usted que existe esta enfermedad?

\subsubsection{Ventajas, sesgos e inconvenientes del uso de medios electrónicos}

Dado el interés de los investigadores en conocer la percepción de las personas adultas, se consideró que su condición de anonimato no influiría en las respuestas, y que los medios electrónicos respondían a los intereses de la investigación. La duda más importante acerca de los cuestionarios en línea distribuidos por un medio electrónico es que, dado que las personas no tienen ninguna presión para resolverlos, están en libertad de hacerlo o no. El éxito de la respuesta depende del interés en el tema.

Un inconveniente del anonimato es el que la persona que responde pueda tomarse la encuesta con poca seriedad. Se dio solamente un caso de este tipo de interlocutor y fue excluido del registro. Otro problema, ya mencionado, es el de la representatividad: puesto que no se trata de una muestra construida aleatoriamente, podría denominarse una muestra por conveniencia (Casal \& Mateu, 2003), donde el método de identificación de las personas encuestadas es el de bola de nieve.

La principal limitación de este tipo de metodología es, así, el sesgo en la muestra debido a que el investigador no tiene control de la población objetivo, como en una encuesta tradicional aleatorizada. El sesgo más importante radica en que la población que respondió debía contar con un celular con ciertas características, o con acceso a internet, además de saber leer y escribir, elementos que pueden reconocerse en el cuadro de características sociodemográficas (cfr. Tabla 1). 
Meza Palmeros, J. A.; Freyermuth Enciso, M. G.; Torres López, G. A.

Tabla 1

México. Distribución de frecuencias absolutas y relativas de los encuestados según características sociodemográficas. 2020

\begin{tabular}{|c|c|c|c|}
\hline Variable & Categoría & $\mathbf{N}$ & $\%$ \\
\hline \multirow[b]{2}{*}{ Sexo } & 1. Masculino & 312 & 32.4 \\
\hline & 2. Femenino & 649 & 67.5 \\
\hline \multirow{2}{*}{$\begin{array}{l}\text { Hablante de lengua } \\
\text { indígena }\end{array}$} & 1. Sí & 35 & 3.6 \\
\hline & 2. No & 927 & 96.4 \\
\hline \multirow{6}{*}{ Escolaridad } & Primaria completa & 2 & .2 \\
\hline & Secundaria completa & 19 & 2.0 \\
\hline & Bachillerato o Preparatoria incompleto & 2 & .2 \\
\hline & Bachillerato o Preparatoria completo & 121 & 12.6 \\
\hline & Profesional & 403 & 41.9 \\
\hline & Posgrado & 414 & 43.0 \\
\hline \multirow{4}{*}{ Religión } & 1. Católica & 513 & 53.3 \\
\hline & 2. Protestante y/o Evangélica & 51 & 5.3 \\
\hline & 3. Costumbre & 30 & 3.1 \\
\hline & 4. Ninguna & 367 & 38.1 \\
\hline \multirow{8}{*}{ Edad agrupada* } & $10-19$ & 16 & 1.7 \\
\hline & $20-29$ & 108 & 11.2 \\
\hline & $30-39$ & 222 & 23.1 \\
\hline & $40-49$ & 247 & 25.6 \\
\hline & $50-59$ & 212 & 22.0 \\
\hline & $60-69$ & 126 & 13.1 \\
\hline & $70-79$ & 24 & 2.5 \\
\hline & $80-89$ & 3 & .3 \\
\hline
\end{tabular}

Fuente: Elaboración propia a partir de encuesta online de percepción del riesgo ante COVID-19

* Se excluyen 3 casos que no proporcionaron información 


\subsection{Procesamiento de datos}

Se llenaron 963 encuestas. Aunque el número de no respuestas difiere dependiendo del reactivo, en ningún caso fue mayor de $4 \%$. Las preguntas cerradas se sistematizaron en tablas de frecuencias mediante el programa SPSS. En ninguna de las dos preguntas cualitativas las respuestas excedieron los 500 caracteres.

Se partió de los supuestos de la pragmática, teoría que señala que el hablar es el hacer, y que los enunciados poseen un significado literal o proposicional (Calsamiglia y Tusón, 2012:34). La sistematización se hizo a través de codificaciones facilitadas por el comando "resúmenes" del SPSS.

\subsubsection{Pregunta ¿Qué sabe del coronavirus?}

Para esta pregunta se obtuvo respuesta en 938 cuestionarios. Las respuestas se codificaron en once categorías; en una respuesta podía haber hasta tres categorías. De este primer filtro se identificaron palabras claves, lo que permitió ubicar las respuestas de una manera más comprehensiva.

\section{Perspectivas}

Estas categorías se organizaron conforme a tres grandes perspectivas:

- Epidemiológica, incluyendo la distribución, los determinantes y la prevención.

- Clínica, incluyendo la etiología, la nosología y el diagnóstico.

- Social, incluyendo aspectos relacionados con las conductas y las interacciones sociales.

\subsubsection{Pregunta ¿Por qué cree que existe esta enfermedad?}

Esta pregunta fue contestada por 935 personas. Las respuestas se codificaron de acuerdo con la naturaleza de la explicación formulada. En un primer momento, se identificaron 49 categorías. Los elementos causales expresados por las personas encuestadas se agruparon de manera exhaustiva a partir de conceptos claves como virus, guerra, animales exóticos, etc. Una vez identificados estos conceptos, las respuestas se revisaron de nueva cuenta para verificar que todas pudieran agruparse en una matriz. 


\section{Modelos explicativos}

Se reconocieron cuatro modelos explicativos en la matriz:

- El primero fue el modelo moral, cuya explicación se centra en transgresiones normativas que distinguen con claridad un comportamiento sujeto a sanción como la causa fundamental de la pandemia. En este modelo se identificaron cuatro tipologías que implican rebasar fronteras de comportamiento: a) alimentarias e higiénicas, b) límites geográficos, c) interpersonales, y d) sociales.

- El segundo fue el modelo determinista, que explica aquellos sucesos que las conductas humanas no pueden controlar. En este modelo se identificaron dos tipologías: a) el determinismo biológico, y b) el destino o la suerte.

- El modelo agencial se definió como el de aquellos sucesos que pueden explicarse por la acción directa de las personas. En este modelo se distinguieron dos categorías: a) como un elemento de creación intencional en laboratorio, o b) como creación de los medios de comunicación, como falsa noticia.

- El modelo xenofóbico se definió como el de las razones étnicas en dos vertientes: las costumbres colectivas o la pertenencia a un grupo racial.

Tres investigadores codificaron de manera independiente cada una de las respuestas de acuerdo con los modelos y sus tipologías, utilizando definiciones operativas elaboradas con este fin. Las discrepancias se rectificaron por consenso y, finalmente, las respuestas se capturaron en la base de datos de acuerdo con sus códigos.

\section{Resultados}

De las 963 personas que respondieron la encuesta, $32.4 \%$ eran hombres y $67.5 \%$ mujeres. El 15\% tenían una escolaridad de bachillerato o menor, $41.9 \%$ tenían un grado profesional, y $43 \%$ un posgrado. En cuanto a la religión, el mayor porcentaje (53\%) profesaba la religión católica, y 38.1\%, ninguna. El rango de edad abarcó de los 15 a los 83 años, con una mediana de 44 y una media de 45 . La moda fue de 40 años, y $70 \%$ de los encuestados se encontraban en el rango de los 30 a los 59 años. Solo 3.6\% de esta población era hablante de alguna lengua indígena (Tabla 1). 
En cuanto a la ocupación, casi $60 \%$ eran profesionistas o técnicos profesionales. Entre ellos destacan docentes, consultores, activistas, profesionales de la salud y estudiantes de posgrado. Del total, $15.3 \%$ se autodefinieron como emprendedores de negocios; $6 \%$ se dedicaban al hogar; $3.2 \%$ no trabajaban, y menos de $2 \%$ estaban buscando trabajo. Aunque se obtuvieron respuestas de prácticamente todas las regiones del país, las zonas centro y sur estuvieron sobrerrepresentadas, con $70 \%$ de las encuestas (Tabla 2).

Tabla 2.

México. Distribución de frecuencias absolutas y relativas de los encuestados según ocupación y región de residencia. 2020

\begin{tabular}{llrr}
\hline Variable & Categoría & N & \% \\
\hline & Funcionarios, directores y jefes & 34 & 3.5 \\
& Profesionistas y técnicos & 553 & 57.4 \\
& Trabajadores auxiliares en actividades administrativas & 29 & 3.0 \\
& Comerciantes, empleados en ventas y agentes de ventas & 191 & 19.8 \\
& Trabajadores en servicios personales y vigilancia & 29 & 3.0 \\
& Trabajadores en actividades agrícolas, ganaderas, & 4 \\
Ocupación** & & .4 \\
& forestales, caza y pesca & 8 & .8 \\
& Trabajadores artesanales y artistas & 7 & .7 \\
& Operadores de maquinaria industrial, ensambladores, & \\
& choferes y conductores de transporte & 16 & 1.7 \\
& Busca trabajo & 31 & 3.2 \\
& No trabaja & 58 & 6.0 \\
& Ama de casa & 960 & 99.7 \\
& Total & & \\
& & 301 & 31.3 \\
& Centro & 92 & 9.6 \\
& Occidente & 58 & 6.0 \\
Región del país a & Noreste & 62 & 6.4 \\
la que pertenece & Noroeste & 380 & 39.5 \\
& Sur & 59 & 6.1 \\
\hline & Sureste & 5
\end{tabular}

Fuente: Elaboración propia a partir de encuesta online de percepción del riesgo ante COVID-19

* Se excluyen 3 casos que no proporcionaron información 
De las personas encuestadas, $90 \%$ vivían acompañadas. Como puede apreciarse en la Tabla 3, la mayor parte de los habitantes de las unidades domésticas se encuentraban en edad reproductiva (entre los 15 y los 49 años), mientras que los grupos de menores de 15 años y de más de 60 representaron $27 \%$ cada uno. Del total de las personas encuestadas $18 \%$ padecían una enfermedad crónica y $26 \%$ convivían con alguna persona con una enfermedad de este tipo (Tabla 4). Cinco morbilidades constituyeron $80 \%$ de los padecimientos reportados, en orden de importancia: hipertensión arterial, diabetes o prediabetes, alergias y enfermedades autoinmunes (Tabla 5). Entre quienes presentaron alguna morbilidad (175), $82 \%$ consideraron que esta constituía un riesgo para adquirir la COVID-19.

Tabla 3.

México. Distribución de frecuencias absolutas y relativas de los encuestados según condiciones de convivencia y por grupos de edad, 2020

\begin{tabular}{clll}
\hline Variable & Categoría & $\mathbf{N}$ & $\%$ \\
\hline \multirow{2}{*}{ Usted vive sólo o acompañado } & Solo & 93 & 9.7 \\
& Acompañado & 869 & 90.3 \\
Grupos de edad de las personas & De 0 a 14 años & & \\
que conviven con él o la & De 15 a 49 años & 267 & 19.7 \\
entrevistada** & De 50 a 59 años & 639 & 47.2 \\
& De 60 y más & 184 & 13.6 \\
\hline
\end{tabular}

Fuente: Encuesta online de percepción del riesgo ante COVID-19

** Un entrevistado puede convivir con personas de varios grupos de edad, la suma puede ser mayor a la $\mathrm{N}$ total

Tabla 4.

México. Distribución de frecuencias absolutas y relativas de los encuestados según condiciones de convivencia y presencia de enfermedades crónicas, 2020

\begin{tabular}{llll}
\hline Variable & Categoría & N & \% \\
\hline & & & \\
Presencia de enfermedades & En las personas con las que convive & 250 & 25 \\
Crónicas*** & La persona entrevistada & 173 & 18 \\
\hline
\end{tabular}

Fuente: Elaboración propia a partir de encuesta online de percepción del riesgo ante COVID-19

*** No todos los casos respondieron

$\mathrm{N}=963$

ISSN 1405-6690 impreso 
Tabla 5.

México. Distribución de frecuencias absolutas y relativas de los encuestados según condiciones de convivencia y presencia de enfermedades crónicas, 2020

\begin{tabular}{|c|c|c|c|}
\hline Variable & Categoría & $\mathbf{N}$ & $\%$ \\
\hline \multirow{15}{*}{$\begin{array}{l}\text { Tipo de enfermedades } \\
\text { crónicas que padecen } \\
\text { algunos de los } \\
\text { entrevistados* }\end{array}$} & Hipertensión & 69 & 33.33 \\
\hline & Diabetes o prediabetes & 46 & 22.22 \\
\hline & Asma, Bronquitis crónica & 20 & 9.66 \\
\hline & Alergias & 16 & 7.73 \\
\hline & Otro & 14 & 6.76 \\
\hline & Enfermedad autoinmune & 10 & 4.83 \\
\hline & Enfermedades de la tiroides & 8 & 3.86 \\
\hline & Enfermedad cardiovascular & 8 & 3.86 \\
\hline & Problemas de salud mental & 4 & 1.93 \\
\hline & EPOC & 4 & 1.93 \\
\hline & Obesidad & 3 & 1.45 \\
\hline & Cáncer & 2 & 0.97 \\
\hline & Tabaquismo & 1 & 0.48 \\
\hline & Inmunodeficiencia & 1 & 0.48 \\
\hline & VIH & 1 & 0.48 \\
\hline
\end{tabular}

Fuente: Elaboración propia a partir de encuesta online de percepción del riesgo ante COVID-19

* Solamente se incluyen las respuestas de las personas con enfermedades crónicas

\subsection{Conocimiento del coronavirus}

\subsubsection{Situación hasta el 29 de marzo de 2020}

Para el pasado 29 de marzo, destacaba en México la publicación de varios decretos del Gobierno Federal que señalaban la epidemia de COVID-19 como una emergencia sanitaria. Las entidades federativas con personas que dieron positivo al SARS-COV-2 fueron, en orden de importancia, la Ciudad de México, Estado de México, Jalisco, Baja California Sur y Puebla. El mayor número de fallecidos correspondió a la Ciudad de México, con 22, y al estado de México, con 7. El número promedio de fallecidos por día era de 5 (SS, 2020). 
Meza Palmeros, J. A.; Freyermuth Enciso, M. G.; Torres López, G. A.

\subsubsection{El conocimiento a finales de marzo y principios de abril}

Entre el 29 marzo y los primeros días de abril, prácticamente todas las personas encuestadas (97\%) tenían conocimiento de la situación en que se encontraba el país con respecto a la COVID-19; solamente 27 personas (2.8\%) carecían de información. Estas personas compartían las mismas características de distribución del resto de las personas encuestadas: tenían entre 17 y 74 años, y distintas profesiones y grados de escolaridad. Diferían en que 63\% habitaban en el sur del país y presentaban un menor porcentaje en el padecimiento de enfermedades crónicas (13\% versus 18\%), y en la convivencia con un enfermo crónico (18\% versus 26\%).

\subsection{3. ¿Qué sabe usted del coronavirus?, respuestas y fuentes}

En el Tabla 6 se muestra la agrupación de las respuestas de las personas encuestadas a la pregunta ¿Qué sabe usted del coronavirus? Algunas se refirieron hasta a tres temas distintos de la enfermedad (15\%), y tenían abundante información del inicio del padecimiento, el agente patógeno, las denominaciones de la enfermedad, el cuadro clínico, los grupos vulnerables y el impacto que se puede esperar de la pandemia. Sus fuentes de información más importantes fueron los boletines de la OMS, el internet, las conferencias de la Secretaría de Salud (SS) y las revistas especializadas. Cabe señalar que 25 de estas personas (2.5\%) trabajaban en el sector salud. 
Tabla 6.

México. Distribución de frecuencias absolutas y relativas de los encuestados según conocimiento sobre el coronavirus por modelo explicativo y tipología. 2020

\begin{tabular}{llrr}
\hline Modelo & Categoría & N* & \% \\
\hline Epidemiológicos & Determinantes de la enfermedad (contagiosa) & 579 & $62 \%$ \\
Clínico & Agente etiológico (aspectos referentes al virus) & 491 & $52 \%$ \\
Epidemiológicos & Distribución (en grupos vulnerables) & 257 & $27 \%$ \\
Clínico & Nosología (signos y síntomas de la enfermedad) & 177 & $19 \%$ \\
Epidemiológicos & Distribución (carácter pandémico) & 111 & $12 \%$ \\
Epidemiológicos & Determinantes (medios de trasmisión) & 107 & $11 \%$ \\
Social & Costumbres alimentarias (consumo de animal exótico en China) & 72 & $8 \%$ \\
Epidemiológicos & Medidas de prevención & 43 & $5 \%$ \\
Clínico & Tratamiento (incurable, no hay vacuna ni tratamiento) & 42 & $4 \%$ \\
Social & Determinantes (relacionadas a la higiene) & 20 & $2 \%$ \\
Social & Impacto (crisis económica y un colapso a los sistemas de salud) & 19 & $2 \%$ \\
No conoce & & 25 & $3 \%$ \\
Total & & 938 &
\end{tabular}

Fuente: Elaboración propia a partir de encuesta online de percepción del riesgo ante COVID-19

El número total de respuestas es mayor a la $\mathrm{N}$ ya que cada encuestado incluyo varios aspectos. $\mathrm{N}=938$

\subsubsection{Conocimiento de los factores destacados: epidemiológico, clínico y social}

Como se aprecia en el Tabla 6, los conocimientos de las personas entrevistadas versaron en tres factores de la salud: el epidemiológico, el clínico y el social. Las respuestas más frecuentes se centraron en el aspecto epidemiológico, particularmente en la contagiosidad y gravedad, que correspondió a $62 \%$ de las menciones. Por su carácter infeccioso, fue señalado como muy contagioso o altamente contagioso, y este término se asoció a los portadores y los grupos vulnerables. En $12 \%$ de las encuestas las personas se refirieron a la COVID-19 como una pandemia, así declarada por la OMS el pasado 11 de marzo.

\subsubsection{Conocimiento de quiénes tienen mayor riesgo de enfermar}

La gravedad de la COVID-19 puede llevar a la muerte. De ahí que en 27\% de las encuestas se aludiera a la distribución de la enfermedad (es decir, a quiénes estaban en riesgo o eran susceptibles de ser afectados más severamente por el coronavirus). Las menciones fueron: 
“personas mayores”, “de la tercera edad”, “mayores de 50”, “de 60 años”, “de 65 años”, “personas con el sistema inmunológico deprimido”, "personas enfermas”, “diabéticas”, “con asma”, ” fumadores”, “VIH”, “obesidad”, “con enfermedades crónicas”, “cardiovasculares”, “EPOC”, ” hipertensos”, “con cáncer”, “embarazadas”, e “inmunodeprimidos y con VIH”. Los menos se preguntaron si era casualidad que las personas mayores y las vulnerables fueran las posibles víctimas, o si la presencia de este virus no era parte de una política demográfica intencionada.

\subsubsection{Conocimiento sobre quiénes tienen mayor riesgo de contagiar}

Las menciones con respecto a quiénes representan un riesgo como contagiantes fueron: "los que tienen SARS-CoV-2 positivo”, "infectados que dejan al virus al toser o estornudar”, "los portadores asintomáticos que representan una amenaza para otros", "los portadores aquellos a los que el virus no les toca pero que se reproduce y se trasmite a través de ellos", "los enfermos que entran en contacto con los objetos", "los objetos son infectados y son trasmisores de la enfermedad", "las gotículas que caen en las distintas superficies y son recogidas por otras personas", "la propagación de persona a persona”, "las personas que se movilizan, sean mexicanos migrantes o extranjeros" (que "un alemán fue quien lo llevó a Puebla”, o que “es una enfermedad de las personas ricas que viajan”).

\subsubsection{Conocimiento de los vehículos del virus y las vías de acceso de la enfermedad}

En $11 \%$ de las encuestas (Tabla 5) se mencionan las mucosas, las secreciones, los fluidos, la saliva y las lágrimas como vehículos del virus (los mismos para adquirirla o transmitirla) y los ojos, la nariz y la boca como vías de acceso de la enfermedad.

\subsubsection{Conocimiento de las medidas preventivas}

La visión del peligro de contagio se entrelazó con la de las medidas preventivas, aunque para cuando se terminó la encuesta, estas últimas se habían expresado poco (5\%). La sana distancia (un metro, 1.5 metros y 2 metros) se percibe como una medida preventiva. El lavado de las manos frecuente conduce a vincular el padecimiento con la falta de higiene. El 
aislamiento (tanto para quienes están sanos como para quienes padecen la enfermedad) es la forma de vida durante la cuarentena. El uso de cubrebocas fue considerado como medida preventiva solo por dos personas.

\subsubsection{Conocimiento de los aspectos clínicos}

\section{$\underline{\text { La etiología }}$}

Entre los aspectos clínicos, el etiológico es el más referido. El 52\% de las menciones aluden al "novel virus", “el virus mutante”, "virus contagioso”, "el virus que se propaga”, "el virus que entra por los ojos, nariz y boca”, "el virus que no es un organismo vivo”, "el virus peligroso”, “virus originado en China”, “el virus que ataca”, “el virus que mata a la gente”, “el virus de RNA". El virus es el agente de las desgracias producidas por esta pandemia; ingresa y se propaga, se aprovecha de algunos, y a otros los convierte en armas mortíferas en contra de los más vulnerables (Tabla 5).

\section{$\underline{\text { Los signos y los síntomas de la enfermedad }}$}

En cuanto a los signos y síntomas que aparecen cuando se es víctima del coronavirus, identificados en $19 \%$ de los encuestados, los más señalados fueron: "un problema del sistema respiratorio", "una enfermedad pulmonar", "la fiebre”, "la gripe”, "la dificultad al respirar”, “sintomas parecidos a la influenza”, "el dolor de cabeza”, y "el dolor de garganta".

Está ausente la mención de la fatiga, que es un síntoma común y puede acompañar a pacientes con COVID-19 sin tos, incluso cuando ya presentan neumonía (Wei et al., 2020).

\section{$\underline{\text { La falta de tratamientos y vacuna }}$}

Solo $4 \%$ de las personas mencionaron la actual falta de un tratamiento eficaz y de una vacuna, rasgos fundamentales de la epidemia: "no es curable”, "que no hay actualmente vacuna”, "pero que no es tan mortal", "no hay vacuna ni tratamiento", "no tiene tratamiento de erradicación y su cura depende de la respuesta del paciente”. 
Meza Palmeros, J. A.; Freyermuth Enciso, M. G.; Torres López, G. A.

\section{Porcentajes de: mortalidad, riesgo, síntomas, medidas profiláctica}

La noción sobre porcentajes está presente en el conocimiento de las personas. Se mencionan los relativos a:

- La mortalidad: “de 2, 3 a $10 \%$, dependiendo del país”; "letalidad mencionada de 5 a $5.5 \%$.

- El riesgo: "80\% van a desarrollar sintomatología leve, el 13 o 16\% va a requerir asistencia médica u hospitalización por sintomatología moderada o neumonía”, "del 4 al 7\% requerirá asistencia con respiradores”.

- La sintomatología y las complicaciones: "en los contagiados el 30\% puede perder el olfato", "el 15\% puede tener neumonía".

- Las medidas profilácticas: "hay que usar gel antibacterial al 70\%”.

Como puede apreciarse, el léxico característico de la epidemiología se va incorporando en el acervo de conocimientos de las personas durante la pandemia.

\subsubsection{Conocimiento de los factores sociales}

\section{$\underline{\text { El origen }}$}

Hay pocas menciones de los factores sociales de la epidemia. En 8\% de las encuestas se vincula sobre todo a:

- China: "que el virus tiene procedencia China”, "que fue en Wuhan y se esparce por todo el mundo”, “se origina, se generó, se dispersó, surgió, o se descubrió en China”, "que fue llevado de Estados Unidos a China”.

- Los animales: "que se transmite de animales a humanos", "que puede infectar a animales y a humanos", o “que fue a través de un murciélago o pangolín”.

\section{$\underline{\text { Impacto social }}$}

La crisis económica y el posible impacto social de la pandemia se mencionaron marginalmente. Solo $2 \%$ señaló que la epidemia conlleva una crisis económica y de los servicios de salud: "que es la crisis del capitalismo", "una crisis social que conlleva una crisis en los sistemas de salud". 


\subsection{Explicaciones causales}

\subsection{1. ¿Por qué cree usted que existe esta enfermedad?}

Identificamos cuatro tipos de atribuciones causales con que la población encuestada explica la pandemia. A partir de las respuestas a la pregunta ¿Por qué cree usted que existe esta enfermedad?, integramos cuatro modelos explicativos: moral, determinista, agencial y xenofóbico.

\subsubsection{El modelo moral}

La explicación se centra en transgresiones a normativas y distingue con claridad un comportamiento sujeto a sanción como la causa fundamental de la pandemia. Este modelo explicativo es el más frecuente entre la población $(n=377 / 40.3 \%)$. Se identificaron tres tipologías de este modelo, según la naturaleza de la transgresión:

1. La alimentaria e higiénica (por ejemplo: "por comer animales exóticos") representa $9.1 \%$ de las respuestas $(\mathrm{n}=88)$.

2. La que consiste en rebasar límites geográficos o físicos (por ejemplo: “...deterioro de las condiciones ambientales, reducción del hábitat para especies silvestres, salto de especie presumiblemente de murciélagos a humanos y transmisión en zonas densamente pobladas”), ( $\mathrm{n}=101 / 10.5 \%)$.

3. La interpersonal, que se identificó cuando la explicación se centró en un comportamiento sancionable en las relaciones humanas (por ejemplo: "Por ignorancia e irresponsabilidad” o “por falta de empatía”), (n=161/16.7\%).

Las transgresiones sociales $(n=30 / 3.1 \%)$, por su parte, implican un comportamiento sancionado de naturaleza colectiva; por ejemplo: "por la globalización”.

\subsubsection{El modelo determinista}

La explicación alude a situaciones que están fuera del control humano ( $n=362 / 38.7 \%$ ), con tres variantes:

1. Situaciones de naturaleza biológica como, por ejemplo: "Porque forma parte de los procesos evolutivos en donde los virus mutan y generan enfermedades que 
anteriormente no se presentaban asi”, ( $(\mathrm{n}=352 / 37.8 \%)$.

2. Situaciones relativas al destino o la suerte se mencionaron en tres ocasiones $(0.3 \%)$.

3. Situaciones de naturaleza religiosa o divina; por ejemplo: "es la voluntad de Dios", $(n=4 / 0.4 \%)$.

\subsubsection{El modelo agencial}

En el modelo agencial la explicación sí recae en acciones humanas (n=167/17.8\%). En este modelo distinguimos tres tipos:

1. Cuando la respuesta explicita la intención deliberada de un agente $(n=65 / 6.7 \%)$ : “...por laboratorio en China para disminuir la población (intencional), y convertirla en pandemia, guerra biológica entre otras...".

2. Cuando se alude a una pérdida de control o un accidente. Por ejemplo: "Por un virus, regado en un laboratorio y que escapó. No vino de un animal en un mercado público, no cuadra su comportamiento”, (n=99/10.3\%).

3. Cuando se alude a un invento o a la creación de los medios de comunicación, $(n=1 / 0.1 \%)$.

\subsubsection{El modelo xenofóbico}

En el modelo xenofóbico la explicación es exclusivamente étnica. Alude a la nacionalidad (china) o a características "culturales" atribuidas a los asiáticos. $(n=29 / 3.1 \%)$. Este modelo integra respuestas tales como "por los chinos", que denotan una atribución étnica ambigua $(n=21 / 2.2 \%)$, o aquellas que hacen explícita una naturaleza colectiva $(n=6 / 0.6 \%)$; por ejemplo: "Por la mala higiene de los asiáticos".

En el Tabla 7 se muestra una tabla de contingencia que indica las tipologías de los diez modelos explicativos señalados por $99 \%$ de la población encuestada. Es decir, concentra las atribuciones causales que más se mencionaron. Como puede apreciarse, el determinismo biológico es el modelo explicativo más utilizado, y el religioso es, en cambio, el menos mencionado. 
Tabla 7.

México. Distribución de frecuencias absolutas y relativas de los encuestados según percepciones de causalidad de los encuestados según modelos y tipologías con mayor poder explicativo. 2020

\begin{tabular}{lcccccc}
\hline \multicolumn{1}{c}{ Tipologías } & $\begin{array}{c}\text { Modelo } \\
\text { Moral }\end{array}$ & $\begin{array}{c}\text { Modelo } \\
\text { Determinista }\end{array}$ & $\begin{array}{c}\text { Modelo } \\
\text { Agencial }\end{array}$ & $\begin{array}{c}\text { Modelo } \\
\text { xenofóbico }\end{array}$ & \% & $\begin{array}{c}\text { \% } \\
\text { acumulado }\end{array}$ \\
\hline Biológico & 0 & 352 & 0 & 0 & 37.6 & 37.6 \\
Transgresiones & 161 & 0 & 0 & 0 & 17.2 & 54.9 \\
interpersonales & & & & & &
\end{tabular}

Transgresiones a

barreras físicas y

geográficas

$\begin{array}{llllll}101 & 0 & 0 & 0 & 10.8 & 65.7\end{array}$

Pérdida de control o

accidente

0

0

99

0

10.6

76.3

Transgresiones

alimentarias e

higiénicas

$\begin{array}{llllll}85 & 0 & 0 & 0 & 9.1 & 85.3\end{array}$

Intencional

0

65

7.0

92.3

Transgresiones sociales

30

0

0

3.2

95.5

Responsabilidad de la

población China

0

0

0

21

2.2

97.8

Insalubridad y cultura

de los asiáticos

$\begin{array}{llllll}0 & 0 & 0 & 6 & 0.6 & 98.4\end{array}$

Religioso

0

4

0

0

0.4

98.8

Fuente: Encuesta online de percepción del riesgo ante COVID-19 $\mathrm{n}=935$ 


\section{Discusión}

El 28 de febrero se inicia la campaña informativa permanente del gobierno federal mediante conferencias de prensa trasmitidas diariamente a las 19 horas. Al momento de empezar la encuesta, se habían transmitido 31 conferencias de prensa. En ellas se señaló que esta epidemia podía no ser considerada de emergencia nacional y que el coronavirus parecía ser menos letal que la influenza H1N1. ${ }^{3}$

En solo 18 días cambió la perspectiva inicial. El 16 de marzo se echaron a andar las medidas para mitigar la epidemia. Se estableció el distanciamiento social y se publicó un acuerdo para suspender la asistencia a las escuelas (Diario Oficial de la Federación (DOF, 16/03/2020). El 23 de marzo, el Consejo de Salubridad General (CSG) difundió el acuerdo por el que se reconocía la epidemia por el virus SARS-COV-2 (COVID-19) en México como una enfermedad grave de atención prioritaria, y se delinearon las actividades de preparación y respuesta (DOF, 23/03/2020). El 24 de marzo la SS estableció las medidas preventivas de sana distancia (DOF, 24/03/2020); y el 31 de marzo se publicaron las acciones extraordinarias para atender la emergencia sanitaria y se definieron las actividades no esenciales (DOF, 31/03/2020).

En el acuerdo del $1^{\circ}$ de abril se ampliaba el periodo suspensivo del 27 de marzo al 30 de abril (DOF, 1/04/2020). La pandemia estaba ya presente en México, con 1925 casos confirmados como positivos por SARS-COV-2, y 44 fallecidos (SS, 2020), y se implementaba la campaña de Sana Distancia.

Los autores de este trabajo consideran que esta comunicación intensiva, y al mismo tiempo contradictoria, por parte de las autoridades sanitarias ha contribuido notablemente a definir los conocimientos de la población acerca de la pandemia, así como las causas que le atribuye, que encontramos en la encuesta.

\footnotetext{
${ }^{3}$ Consultar la conferencia de prensa de la Secretaría de salud del 28 de febrero 2020. 


\subsection{Hallazgos relevantes para orientar la comunicación}

De entre los hallazgos de la presente exploración, los autores consideran que dos son particularmente relevantes para la coyuntura actual, ya que pueden orientar las intervenciones para comunicar los riesgos e informar a la población.

1. En primer lugar, el que los conocimientos de la población acerca de la pandemia correspondan en gran medida al discurso biomédico, lo que puede apreciarse en el énfasis puesto en los aspectos clínicos y epidemiológicos en sus respuestas. La estrategia de comunicación de la SS -dos veces al día, por la mañana y en la noche-, además de la constante discusión que ha tenido lugar en los medios de comunicación con relación a esta información, muy posiblemente contribuyó a que las personas encuestadas tuvieran tales perspectivas. Hay que tener en cuenta también que, durante el levantamiento de las encuestas, una parte de las personas entrevistadas estaban en cuarentena y dispusieron de tiempo para dar seguimiento a los medios de comunicación electrónicos. Medios que generaron la reproducción masiva de esta información que, los autores han argumentado, transita por múltiples resignificaciones (Barrios y Hochberg, 2020; Geldsetzer, 2020; Huynh, 2020; Van Babel et al., 2020; Zhong et al., 2020).

La influencia de esta estrategia no solo se reconoce en el conocimiento manifestado por la población, sino también en las atribuciones causales predominantes entre las personas encuestadas, que se centran en el determinismo biológico, característico del modelo explicativo predominante de la biomedicina (Achard, 1980; Gaines y DavisFloyd, 2004; Menéndez, 1990). Hallazgos similares fueron documentados en torno a la epidemia de influenza H1N1, aunque en un momento más tardío de su desarrollo (Agüero Santagelo et al., 2009).

La comunicación informativa que la ss realizó tempranamente fue persuasiva y contó con credibilidad. Su discurso giró en torno a la epidemiología y la medicina basada en la evidencia. Esta credibilidad se manifiesta en la penetración del discurso biomédico en la población, en particular respecto a la COVID-19 (Van Babel et al., 2020), evidente en los resultados de la encuesta. Los autores consideran que este es un aspecto positivo de la interacción comunicativa entre las autoridades sanitarias y la población en el periodo temprano de la epidemia. En contraste con lo documentado en otro tipo de crisis, como 
aquella generada por las "vacas locas" en el Reino Unido, en que la percepción negativa y la poca credibilidad otorgada a las autoridades sanitarias constituyó una dificultad mayor (Bennet, 1999).

Por otro lado, hay que considerar la credibilidad otorgada al discurso epidemiológico transmitido por las autoridades sanitarias, en el contexto actual. Este es aspecto central en la configuración del riesgo percibido por la población como lo señalan trabajos recientes (Shao y Hao, 2020; Alyanak, 2020)

2. En segundo lugar, si bien los medios de comunicación habían mostrado el colapso de los sistemas de salud de otros países a consecuencia de la pandemia (Smith, 2020), esta preocupación -hasta la fecha en que concluyó la encuesta- no se manifiesta en la población que la respondió.

De acuerdo con los resultados preliminares de la encuesta, la preocupación central se enfoca en los aspectos epidemiológicos y clínicos, lo que indica que las situaciones críticas de salud -en este caso relacionadas con la pandemia- son significadas como peligrosas dependiendo de cómo afectan directamente la vida cotidiana de las personas.

Este hallazgo es compatible con algunas reflexiones preliminares sobre la actual pandemia que se han manifestado en el ámbito internacional (Ali, 2020; Alyanak, 2020), si bien no se ha corroborado empíricamente fuera del presente trabajo. No obstante, ha sido uno de los puntos más reiterados en la literatura sobre la percepción del riesgo desde una perspectiva sociocultural (Lupton, 2013).

Los autores del presente trabajo consideran que éste muestra resultados relevantes en una situación novedosa en que la construcción de conocimientos es aún incipiente. Aunque ha habido un avance significativo en los hallazgos microbiológicos, clínicos y epidemiológicos obtenidos hasta la fecha, en el ámbito internacional hay muy poca información sobre las respuestas de la población ante la situación suscitada por la COVID-19. Esto incluye particularmente los abordajes dirigidos a explorar su percepción del riesgo y sus conocimientos. En México el trabajo de Meza-Palmeros (2020), explora la vinculación entre la precariedad material y la construcción de significados en torno a la COVID-19. Exceptuando este trabajo, hasta el momento de redactar este artículo, sus autores no encontraron 
información derivada de estudios en esta línea en el país, que se señalan como fundamentales para comprender los comportamientos de la población ante los riesgos (Covello et al., 2001; Lau et al., 2003; Mahajan et al., 2008; Smith, 2006).

La principal limitación del estudio es el sesgo en el tipo de interlocutor de la encuesta. A pesar de que los instrumentos utilizados son cada vez más populares, pues $65.8 \%$ de la población nacional tienen acceso a ellos (Instituto Nacional de Estadística y Geografía [INEGI], s.f.), siguen siendo herramientas limitadas para la indagación entre las poblaciones más pobres y, por lo tanto, más vulnerables.

Los hallazgos del trabajo deben ser considerados a la luz del sesgo muestral de la presente encuesta. El que se haya difundido de manera digital en las redes de los autores contribuyó a sobrerrepresentar a un grupo poblacional con una mayor escolaridad. Este sesgo está presente en encuestas que han perseguido intereses similares con metodologías parecidas en el ámbito internacional (Geldsetzer, 2020; Zhong et al., 2020).

\section{Conclusiones}

Este estudio muestra las bondades de los medios electrónicos para la investigación en ciertas coyunturas sociales. Además, sugiere que las encuestas de seguimiento podrían ofrecer información valiosa sobre la trasformación de la percepción del riesgo a lo largo de una crisis social producida por la irrupción de un agente biológico nuevo, y de su vinculación con el contexto en el que se vive.

Por un lado, reconoce que en una epidemia la percepción del riesgo está determinada por la fase en que esta se encuentre. Por otro lado, reitera las reflexiones formuladas en otros trabajos respecto a la trascendencia de la comunicación de riesgos en situaciones críticas (Banegas, 1997). En este sentido, como ha señalado Slovic (1986), la percepción de riesgo constituye uno de los aspectos más sensibles con relación a la información que recibe la población y la manera en que esta orienta sus comportamientos. Este estudio también pone de manifiesto la importancia que pueden adquirir los medios de comunicación para trasmitir información en un momento de crisis como el actual.

Finalmente, se muestra la importante penetración del discurso biomédico, particularmente el epidemiológico tanto en los conocimientos, como en las explicaciones 
causales formuladas por la población mexicana, encuestada a principios de la pandemia. Los autores consideran que esta penetración puede ser explicada por la comunicación de riesgos, intensiva e inédita que las autoridades sanitarias han dirigido a la población. Además, como queda manifiesto en el presente estudio, existe una importante credibilidad otorgada a dichas autoridades. En este sentido el estudio reitera el importante efecto que una estrategia comunicativa tiene sobre la percepción del riesgo en la población.

\section{Agradecimientos}

Los autores agradecen a las personas que participaron en la encuesta por su disposición y al Consejo Nacional de Ciencia y Tecnología (CONACYT).

\section{Referencias}

Achard, P. (1980). Discurso biológico y orden social: crítica de las teorías biologistas, psicología y ciencias sociales. México: Editorial Nueva Imagen.

Agüero Santagelo, F., Nebot Adell, M., Pérez Giménez, A., López Medina, M. J., \& García Continente, X. (2011). Actitudes y comportamientos preventivos durante la pandemia de gripe (H1N1) 2009 en España. Revista española de salud pública, 85(1), 73-80.

Ali, I. (2020). The COVID-19 pandemic: Making sense of rumor and fear. Medical Anthropology, 1-4. http://doi.org/10.1080/01459740.2020.1745481

Alyanak, O. (2020). Faith, politics and the COVID-19 pandemic: The Turkish response. Medical Anthropology. http://doi.org/10.1080/01459740.2020.1745482

Bajtin, M. (2011). Las fronteras del discurso. Las Cuarenta Ediciones.

Banegas J. R. (1997). La comunicación de riesgos en salud pública. SEE 10, 1-2.

Barrios, J. M., \& Hochberg, Y. (2020). Risk perception through the lens of politics in the time of the COVID-19 pandemic (No. w27008). National Bureau of Economic Research.

Bennett P (1999). Understanding responses to risk: some basic findings. En Bennett P. \& Calman K. Risk communication and public health. New York: Oxford University Press, p. 3-19. 
Beck, U. (1992). Risk society: Towards a new modernity. London: Sage.

Bradbury, J. A. (1989). The policy implications of differing concepts of risk. Science,

Technology, \& Human $\quad$ Values, 14(4), 380-399. http://doi.org/10.1177/016224398901400404

Calsamiglia, H. T., \& Tusón, A. A. (2008). Las cosas del decir: manual de análisis del discurso. Madrid: Editorial Ariel SA.

Casal, J. \& Mateu, E. (2003). Tipos de muestreo.Rev. Epidem. Med. Prev, 1(1), 3-7.

Covello, V. T., Peters, R. G., Wojtecki, J. G., \& Hyde, R. C. (2001). Risk communication, the West Nile virus epidemic, and bioterrorism: Responding to the communication challenges posed by the intentional or unintentional release of a pathogen in an urban setting. Journal of Urban Health, 78(2), 382-391. http://doi.org/10.1093/jurban/78.2.382

Davison, C., Frankel, S., \& Smith, G. D. (1992). The limits of lifestyle: re-assessing 'fatalism' in the popular culture of illness prevention. Social Science \& Medicine, 34(6), 675-685. http://doi.org/10.1016/0277-9536(92)90195-V

Diario Oficial de la Federación (DOF). (16-03-2020). Secretaría de Educación Pública. Acuerdo número 02/03/20 por el que se suspenden las clases en las escuelas de educación preescolar, primaria, secundaria, normal y demás para la formación de maestros de educación básica del Sistema Educativo Nacional, así como aquellas de los tipos medio superior y superior dependientes de la Secretaría de Educación Pública. México, 16 de abril. Recuperado el 9 de mayo de 2020, de: https://www.dof.gob.mx/nota_detalle.php?codigo=5589479\&fecha=16/03/2020

Diario Oficial de la Federación (DOF). (23-03-2020). Consejo De Salubridad General. Acuerdo por el que el Consejo de Salubridad General reconoce la epidemia de enfermedad por el virus SARS-COV-2 (COVID-19) en México, como una enfermedad grave de atención prioritaria, así como se establecen las actividades de preparación y respuesta ante dicha epidemia. México, 23 de abril. Recuperado el 9 de mayo de 2020 de: $\underline{\text { https://www.dof.gob.mx/nota_detalle.php?codigo=5590161\&fecha=23/03/2020 }}$

Diario Oficial de la Federación (DOF). (24-03-2020). Secretaria de Salud. Acuerdo por el que se establecen las medidas preventivas que se deberán implementar para la mitigación y control de los riesgos para la salud que implica la enfermedad por el virus SARS- 
CoV-2 (COVID-19). México, 24 de abril. Recuperado el 9 de mayo de 2020 de: https://www.dof.gob.mx/nota_detalle.php?codigo=5590339\&fecha=24/03/2020

Diario Oficial de la Federación (DOF).. (31-03-2020). Consejo de Salubridad General. Acuerdo por el que se declara como emergencia sanitaria por causa de fuerza mayor, a la epidemia de enfermedad generada por el virus SARS-COV-2 (COVID-19). México, 31 de abril. Recuperado el 9 de mayo de 2020 de: https://www.dof.gob.mx/nota_detalle.php?codigo=5590745\&fecha=30/03/2020

Diario Oficial de la Federación (DOF).. (01-04-2020). Secretaría de Educación Pública. ACUERDO número 06/03/20 por el que se amplía el periodo suspensivo del 27 de marzo al 30 de abril del año en curso y se modifica el diverso número 02/03/20 por el que se suspenden las clases en las escuelas de educación preescolar, primaria, secundaria, normal y demás para la formación de maestros de educación básica del Sistema Educativo Nacional, así como aquellas de los tipos medio superior y superior dependientes de la Secretaría de Educación Pública. México, 1 de abril. Recuperado el 9 de mayo de 2020, de: https://www.dof.gob.mx/nota_detalle.php?codigo $=5590981 \&$ fecha $=01 / 04 / 2020$

Douglas, M. (2002). Risk and blame. London: Routledge.

Douglas, M. (2003). Purity and danger: An analysis of concepts of pollution and taboo. Routledge.

Drake, F. (2006). Mobile phone masts: Protesting the scientific evidence. Public understanding of $\quad$ science, $\quad$ 387-410. http://doi.org/10.1177/0963662506057246

Gaines, Atwood \& Davis-Floyd, Robbie. (2004). Biomedicine. En Ember, Carol \& Ember, Melvin (Eds.), Encyclopedia of Medical Anthropology: Health and Illness in the World's Cultures Volume I: Topics Volume II: Cultures (95-109). Springer Science \& Business Media

Geldsetzer, P. (2020). Knowledge and perceptions of COVID-19 among the general public in the United States and the United Kingdom: A cross-sectional online survey. Annals of internal medicine. http://doi.org/10.1016/j.jaip.2020.04.001 
Huynh, T. L. (2020). The COVID-19 risk perception: A survey on socioeconomics and media attention. Econ. Economics Bulletin, 40(1), 758-764. Recuperado el 03 de julio 2020, de https://ideas.repec.org/a/ebl/ecbull/eb-20-00175.html

Instituto Nacional de Estadística y Geografía (INEGI). (s.f.). Encuesta Nacional sobre Disponibilidad y Uso de Tecnologías de la Información en los Hogares (ENDUTIH) 2018. Recuperado el 18 de mayo de 2020, de https://www.inegi.org.mx/programas/dutih/2018/

Kleinman, A. (1980). Patients and healers in the context of culture: An exploration of theborderland between anthropology, medicine, andpsychiatry. Berkeley: University of California Press.

Lau, J. T. F., Yang, X., Tsui, H., \& Kim, J. H. (2003). Monitoring community responses to the SARS epidemic in Hong Kong: from day 10 to day 62. Journal of Epidemiology \& Community Health, 57(11), 864-870. http://doi.org/10.1136/jech.57.11.864

Lupton, D. (2012). M-health and health promotion: The digital cyborg and surveillance society. Social Theory \& Health, 10(3), 229-244. http://doi.org/10.1057/sth.2012.6

Lupton, D. (2013). Risk. London: Routledge.

Mahajan, A. P., Sayles, J. N., Patel, V. A., Remien, R. H., Ortiz, D., Szekeres, G., \& Coates, T. J. (2008). Stigma in the HIV/AIDS epidemic: a review of the literature and recommendations for the way forward. AIDS, 22(Suppl 2), S67-S79. http://doi.org/10.1097/01.aids.0000327438.13291.62

Mairal, G. (2011). The history and the narrative of risk in the media. Health, risk \& society, 13(1), 65-79. http://doi.org/10.1080/13698575.2010.540313

Menéndez, E. (1990). Morir de alcohol: saber y hegemonía médica. Ciudad de México: Alianza Editorial Mexicana.

Menéndez, E. L., \& Di Pardo, R. B. (2009). Miedos, riesgos e inseguridades: Los medios, los profesionales y los intelectuales en la construcción social de la salud como catástrofe. Ciudad de México: Centro de Investigaciones y Estudios Superiores en Antropología Social.

Meza-Palmeros, J. A. (2020). Risk perception, coronavirus and precariousness. A reflection on fieldwork under quarantine. Health Sociology Review, 29(2), 113-121. https://doi.org/10.1080/14461242.2020.1785321 
Meza Palmeros, J. A.; Freyermuth Enciso, M. G.; Torres López, G. A.

Secretaría de Salud (SS). (2020). COVID-19 Base de datos. Datos Abiertos. Gobierno de México, Dirección General de Epidemiología. Recuperado de : https://www.gob.mx/salud/documentos/datos-abiertos-152127

Shao, W., \& Hao, F. (2020). Confidence in political leaders can slant risk perceptions of COVID-19 in a highly polarized environment. Social Science \& Medicine (1982), 261, 113235. https://doi.org/10.1016/j.socscimed.2020.113235

Slovic, P. (1986). Informing and educating the public about risk. Risk analysis, 6(4), 403415.

Smith, R. D. (2006). Responding to global infectious disease outbreaks: Lessons from SARS on the role of risk perception, communication and management. Social Science \& Medicine, 63(12), 3113-3123. http://doi.org/10.1016/j.socscimed.2006.08.004

Smith, C. (2020). The structural vulnerability of healthcare workers during COVID-19: Observations on the social context of risk and the equitable distribution of resources. Social Science $\quad \& \quad$ Medicine, 113119. https://doi.org/10.1016/j.socscimed.2020.113119

Van Bavel, J. J., Baicker, K., Boggio, P. S., Capraro, V., Cichocka, A., Cikara, M., ... \& Drury, J. (2020). Using social and behavioural science to support COVID-19 pandemic response. Nature Human Behaviour, 4, 460-471. http://doi.org/10.1038/s41562-020$\underline{0884-Z}$

Wang, D., Hu, B., Hu, C., Zhu, F., Liu, X., Zhang, J., ... \& Zhao, Y. (2020). Clinical characteristics of 138 hospitalized patients with 2019 novel coronavirus-infected pneumonia in Wuhan, China. Jama, 323(11), 1061-1069.

Wei, J., Xu, H., Xiong, J., Shen, Q., Fan, B., Ye, C., ... \& Hu, F. (2020). 2019 novel coronavirus (COVID-19) pneumonia: serial computed tomography findings. Korean Journal of Radiology, 21(4), 501-504.

World Health Organization (WHO). (2020a). Coronavirus disease (COVID-19) Situation Report - 124. World Health Organization. Recuperado 17 de mayo del 2020, de: https://www.who.int/emergencies/diseases/novel-coronavirus-2019/situation-reports 
World Health Organization (WHO). (2020b). Novel Coronavirus (2019-nCoV): situation report, 11. World Health Organization. Recuperado el 17 de mayo del 2020, de: https://apps.who.int/iris/handle/10665/330776

World Health Organization (WHO). (2020c). WHO Director-General's opening remarks at the media briefing on COVID-19 - 11 March 2020. Recuperado el 17 de mayo de 2020, de: https://www.who.int/dg/speeches/detail/who-director-general-s-opening-remarks-atthe-media-briefing-on-covid-19---11-march-2020

Zhong, B. L., Luo, W., Li, H. M., Zhang, Q. Q., Liu, X. G., Li, W. T., \& Li, Y. (2020). Knowledge, attitudes, and practices towards COVID-19 among Chinese residents during the rapid rise period of the COVID-19 outbreak: A quick online cross-sectional survey. International Journal of Biological Sciences, 16(10), 1745-1752. http://doi.org/10.7150/ijbs.45221

Zhou, F., Yu, T., Du, R., Fan, G., Liu, Y., Liu, Z., ... \& Guan, L. (2020). Clinical course and risk factors for mortality of adult inpatients with COVID-19 in Wuhan, China: a retrospective cohort study. The lancet, 395, 1054-1062. http://doi.org/10.1016/S0140-6736(20)30566-3 
Meza Palmeros, J. A.; Freyermuth Enciso, M. G.; Torres López, G. A. 